\title{
Pseudoarylsulfatase-A Deficiency in the Neurologically Impaired Patient
}

\author{
Kevin Farrell, D.A. Applegarth, J.R. Toone, P.M. McLeod, and A.V. Savage
}

\begin{abstract}
The demonstration of low arylsulfatase-A (ASA) activity in leucocytes or fibroblasts is used often to establish the diagnosis of metachromatic leucodystrophy (MLD). However, low ASA activity is observed also in pseudo-ASA deficiency which may be as common as MLD. We report two patients with pseudo ASA deficiency who had abnormal neurological findings consistent with atypical MLD. Because the measurement of ASA activity is neither a sensitive nor specific method with which to establish a diagnosis of MLD, this diagnosis should be confirmed by nerve biopsy, measurement of urinary sulfatide or a cerebroside sulfate loading test, using cultured fibroblasts.
\end{abstract}

RÉSUMÉ: La déficine en arylsulfatase chez le patient atteint neurologiquement La démonstration d'une activité basse en arylsulfatase - A (ASA) dans les leucocytes ou les fibroblastes sert souvent dans le diagnostic de la leucodystrophie métachromatique (MLD). Cependant, une activité ASA basse est également observée dans la pseudo-déficience ASA qui est peut-être aussi fréquente que le MLD. Nous faisons rapport sur deux patients avec pseudo-déficience ASA dont le tableau neurologique était proche de celui du MLD. Puisque la mesure de l'activité ASA est peu sensible et peu spécifique, le diagnostic du MLD devrait toujours être confirmé par une biopsie neurale, la mesure des sulfatides urinaires ou un test de surcharge en cérébroside sulfate sur des fibroblastes en culture.

Can. J. Neurol. Sci. 1985; 12:274-277

Metachromatic leucodystrophy (MLD) is a progressive, neurodegenerative disease characterised by demyelination and deposition of metachromatic granules in the central and peripheral white matter. ' Deficiency of arylsulfatase A (ASA) impairs the metabolism of cerebroside sulfate and has been demonstrated in patients with MLD.' The ability to measure ASA activity in leucocytes and fibroblasts has simplified the diagnosis. However deficiency of ASA activity, per se, is not necessarily diagnostic of MLD. Thus, low ASA activity has been reported in healthy relatives of MLD patients, and in other normal individuals with no family history of MLD. ${ }^{2}$ This finding has been termed pseudoASA deficiency. Because pseudo-ASA deficiency may occur in patients with other neurological disorders, there is a potential for misdiagnosis. ${ }^{3.4}$ We describe two such patients, the methods used to establish that they did not have MLD and discuss a possible relationship between pseudo-ASA deficiency and neurological disease.

\section{Case Reports}

Case 1: A female infant was born at term by vertex vaginal delivery following a normal pregnancy. The Apgar scores were 9 and 10 at one and five minutes respectively. There was no family history of neurological disease. Length, weight and head circumference were at the 50th percentiles. Examination at birth was normal but repeated suctioning of tracheal and oral secretions was required in the first week. Extensor posturing was observed at two weeks and fisting at ten weeks of age. At five months of age, height and weight were at the 25 th percentile. However, the head circumference was at the 3 rd percentile. The infant was visually attentive and had a brisk acoustic startle. Cranial nerve examination was normal. Head control was poor and there was spasticity involving the arms more than legs and brisk deep tendon reflexes. Tonic seizures occurred at six months of age and by three years there were intractable seizures. At this time irritability was more pronounced but she was visually alert and could eye point to many different named objects. There was marked truncal hypotonia with athetoid posturing and increased tone in all limbs.

CT-scan at five months of age showed decreased attenuation in periventricular white matter, particularly around the occipital horns. The ASA level was below the normal range (Table 1). CSF protein was $1.8 \mathrm{~g} / \mathrm{L}$. Nerve conduction velocities were normal in both motor $(41$ $\mathrm{m} / \mathrm{sec})$ and sensory $(39 \mathrm{~m} / \mathrm{sec})$ fibres of the median nerve and in the motor fibres $(47 \mathrm{~m} / \mathrm{sec})$ of the lateral popliteal nerve. Sural nerve biopsy at nine months of age demonstrated no evidence of demyelination or metachromasia. ASA levels in the parents were in the MLD heterozygote range, while those of the normal older sibling were below the normal range (Table 1). Cerebroside sulfate loading tests of the fibroblasts from the proband and sibling showed that they had normal ability to degrade cerebroside sulfate. (Fig 1). Assays for plasma ammonia, amino acids, long chain fatty acids, urinary amino acids, urinary organic acids, leucocyte galactocerebrosidase and serological studies for toxoplasma, rubella, cytomegalovirus and herpes simplex were normal. A second CT scan repeated at 24 months of age showed poorly developed

From the Department of Pediatrics. University of British Columbia (Drs. Farrell and Applegarth); Biochemical Diseases Laboratory, British Columbia's Children's Hospital, Vancouver (Drs. Applegarth. Toone and Savage); Department of Medical Genetics, University of British Columbia (Dr. McLeod)

Received October 18, 1984. Accepted in revised form June, 1985

Reprint requests to: Dr. K. Farrell, Division of Neurology, British Columbia's Children's Hospital, 4480 Oak Street, Vancouver, B.C., Canada V6H 3V4 
Table 1: Aryl Sylphatase A (nmoles/hr/mg protein)

\begin{tabular}{|c|c|c|c|c|}
\hline & Leucocytes & & Fibroblasts & \\
\hline Mother of patient 1 & 38 & & 169.8 & \\
\hline Sister of patient I (age 3 years) & 17.6 & 46.4 & & \\
\hline Patient 2 & 9.4 & & & 12.7 \\
\hline Mother of patient 2 & 85.9 & & & \\
\hline \multirow[t]{2}{*}{ Controls run in the same assay } & & mean (9) 156.4 & $\begin{array}{l}370.5 \\
351.7\end{array}$ & mean (5) 148.2 \\
\hline & & range $99.9-297.5$ & 213.8 & range $85.6-316$ \\
\hline Established control range (n 30) & $\begin{array}{c}\text { mean } 109 \\
\text { range } 51-215\end{array}$ & & & \\
\hline
\end{tabular}

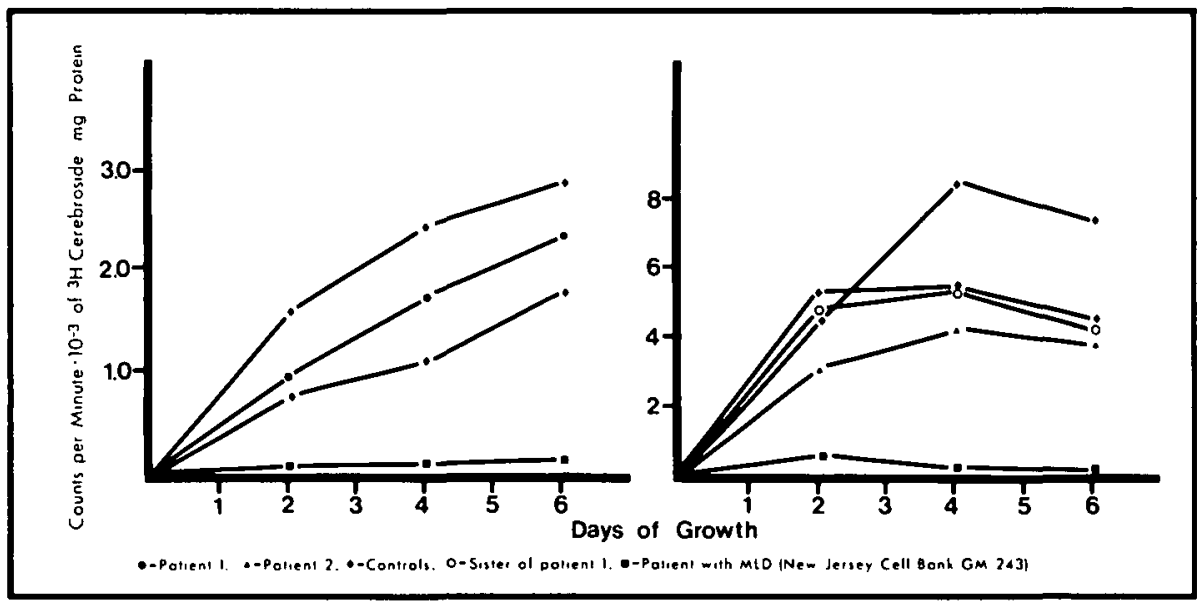

Figure 1

cortical sulci and abnormal differentiation of grey and white matter. This suggested the possibility that the patient had a cerebral dysgenesis.

Case 2: A male infant was born at term following a normal pregnancy. He did not require to be resuscitated. He was of normal weight and no abnormality was noted in the neonatal period. There was no family history of neurological disease. Intractable seizures developed at four months of age. The patient walked at three years, was able to say a few words by five years and at six years his Developmental Quotient was 24 on the Cattell Scale. At sixteen years the gait was broad-based and he had regressed mentally. There was mild hypotonia, the deep tendon reflexes were hypoactive, and plantar responses were downgoing. CSF protein at this time was $0.6 \mathrm{~g} / \mathrm{L}$ and the colloidal gold curve was 23440 . Motor and sensory median nerve conduction and lateral popliteal motor nerve conduction were normal. Over the next two years there was further mental deterioration and the ability to walk was lost. The ASA level in fibroblasts was $10 \%$ of normal value. On this basis, a diagnosis of atypical metachromatic leucodystrophy was made.

The patient was reassessed at 26 years of age when his sisters sought genetic counselling. At this time the patient was confined to bed and unresponsive to command, but would withdraw from pinprick. There were orofacial dyskinesias and dystonic posturing of upper limbs. Tone was increased in the upper limbs and decreased in the lower limbs. The tendon reflexes were brisk in the arms and decreased in the legs. The plantar responses were flexor. ASA levels were in the MLD homozygote range (Table 1). However, the cerebroside sulfate loading test demonstrated normal fibroblast function (Fig 1). Posterior tibial motor nerve conduction and superficial peroneal sensory nerve conduction were normal. Sural nerve biposy showed a decrease in the number of large fibres. Electron microscopy showed no evidence of demyelination or inclusions. CT scan showed minimal dilatation of the lateral ventricles and prominent sulci. Assays for alpha and beta $\mathrm{N}$-acetyl hexosaminidase, beta-galactosidase, acid phosphatase, beta-glucosidase, alpha-glucosidase, alpha-mannosidase, and alpha-fucosidase in leucocytes and fibroblasts yielded normal results.

\section{LABORATORY METHODS}

Leukocytes from $3 \mathrm{ml}$ heparinised venous blood were isolated by sedimentation in $6 \%$ dextran and stored at $-20^{\circ}$ prior to assay. Cells were disrupted by sonication and the supernatant used for assay of ASA. Cultured skin fibroblasts were grown in Eagles essential medium $+12.5 \%$ fetal calf serum. When confluent, the fibroblasts were harvested by trypsinisation and the pellets stored at $-70^{\circ} \mathrm{C}$ prior to assay. Cells were disrupted by three cycles of freeze-thawing and the whole homogenate used for assay of ASA activity. ${ }^{5}$ Galactocerebrosidase activity was assayed by the method of Suzuki. ${ }^{6}$ All other lysosomal enzyme assays were by conventional 4-methyl umbelliferyl fluorometric or spectrophotometric methods. ${ }^{7}$

The cerebroside sulphate loading test was carried out by a modification of the method of Kihara ${ }^{8}$ using ${ }^{3} \mathrm{H}$-cerebroside sulphate labelled in the fatty acid moiety (provided by Dr. D. Farrell, Seattle). For each experiment two negative controls and one positive MLD cell line (Human Genetic Mutant Cell Repository GM 243 - designated NJCB GM 243 in figure 1) were grown with the patients. Patients $I$ and 2 and the sister of 
patient I were tested. Unlabelled cerebroside sulphate (Supelco, Inc. Bellafonte, $\mathrm{PA}$ ) and ${ }^{3} \mathrm{H}$-cerebroside sulphate were dispersed in Eagles MEM $+12.5 \% \mathrm{FCS}$ to give a final concentration of $0.024 \mathrm{mM}$ and $3.5 \times 10^{4}$ counts $/ \mathrm{min} / \mathrm{ml}$. Cultures in $6 \mathrm{~T}^{25}$ flasks per cell line were initiated and after two days growth the medium was replaced by $4 \mathrm{ml}$ of the labelled cerebroside sulphate medium. Duplicate flasks were harvested by trypsinisation and scraping at 2, 4 and 6 days incubation and the washed cell pellets were lyophilised. Cells were extracted and cerebroside sulphate separated from cerebroside by DE 52 chromatography following the method of Poulos and Beckman. ${ }^{9}$ The cellular debris left after extraction was dissolved in $0.1 \mathrm{ml} 2.5 \mathrm{~N} \mathrm{NaOH}$. The solution was neutralised and assayed for protein by the method of Lowry. ${ }^{10}$

\section{Discussion}

Cerebroside sulfate is metabolised by the combined action of heat-labile ASA and a heat-stable nonenzymatic protein activator. Most cases of MLD are due to a deficiency of ASA activity. However, some patients with MLD have ASA activity in the normal or heterozygous range. These patients have been shown to have either a deficiency of cerebroside sulfatase activator protein ${ }^{11.12}$ or a $\mathrm{Km}$ mutant of $\mathrm{ASA}^{13}(\mathrm{Km}$, the Michaelis constant, is a parameter of enzyme function). Thus MLD may occur occasionally in the presence of normal ASA activity. A more common diagnostic dilemma is the occurrence of ASA activity in the homozygote range in a patient without MLD. ${ }^{2}$ Fibroblasts from such an individual hydrolyse sulfatide at a normal rate and this phenotype has been termed pseudo-ASA deficiency. ${ }^{2}$ Langenbeck has proposed that pseudo-ASA deficiency is due to a mutation at the ASA locus resulting in an allele which codes for ASA which has low activity in vitro. ${ }^{14}$ Because the frequency of the pseudo-deficiency allele may be equal to or higher than the frequency of the ASA deficiency allele, ${ }^{15,16}$ low ASA activity may be associated with pseudoASA deficiency as frequently as with MLD.

The two patients reported in this paper had features which led us to measure ASA activity and conclude initially that they might have MLD. Although patient 1 had a static encephalopathy with onset in the neonatal period, the motor system was the most severely involved. A congenital form of MLD has been proposed $^{17.18}$ and the early CT scan changes were similar to those which have been described in metachromatic leucodystrophy.${ }^{19}$ The second patient had a progressive neurological problem and the finding of low ASA activity led to the misdiagnosis of MLD.

Although pseudo-ASA deficiency was described initially in normal relatives of patients with MLD, it has been reported subsequently in neurologically abnormal patients with no family history of MLD ${ }^{1,3,4}$ Indeed, a previously described "atypical variant of MLD" may well have had this combination of pseudo ASA deficiency and a non-MLD neurologic disease. ${ }^{20}$ The relationship between the pseudo-ASA deficiency and the neurological dysfunction in these patients may be coincidental. The healthy sibling of patient 1 and a healthy sibling of one of the previously reported cases also had low ASA activity.' However, Dubois showed that a group of patients with nonMLD neurologic diseases had significantly lower ASA levels than control patients. ${ }^{21}$ In addition, Peiffer described a boy in whom the enzyme levels suggested that he might be a compound heterozygote of MLD and pseudo-ASA deficiency. ${ }^{22}$ In that child, the neuropathological examination of the brain showed a diffuse cerebral sclerosis without the features of MLD. Thus it is possible that pseudo-ASA deficiency may confer an increased risk of a demyelinating or other neurological disorder.

The relatively high incidence of pseudo-ASA deficiency together with the genetic and prognostic implications of MLD emphasize the importance of using a more definitive method to establish the diagnosis of MLD. The cerebroside sulfate loading test can be used to establish the diagnosis of MLD even in the presymptomatic patient or fetus. ${ }^{8}$ Thus cultured fibroblasts from patients with MLD develop metachromatic granules when grown in a medium supplemented with exogenous cerebroside sulfate. This has not been reported in fibroblasts from obligate heterozygotes, controls or patients with pseudo ASA deficiency. ${ }^{2}$ In addition, the cerebroside sulfate loading test has been shown to discriminate between amniotic fluid cells from fetuses with pseudo-ASA deficiency and MLD. ${ }^{8}$

Nerve biopsy is another sensitive and specific method of confirming the diagnosis of MLD. ${ }^{23}$ Although nerve biopsy is an invasive investigation, it can be performed in most centres, whereas the cerebroside sulfate loading test can be done only in a few laboratories. Demonstration of an increased amount of sulfatide in urine can also be used to confirm the diagnosis of MLD.' However, this test is available in relatively few laboratories.

\section{ACKNOWLEDGEMENTS}

We wish to thank Dr. B. P. DeJong for permission to report patient 1 .

\section{REFERENCES}

1. Kolodny EH, Moser HW. Sulfatide lipidosis: metachromatic leucodystrophy, in The Metabolic Basis of Inherited Disease. Sth ed, Edited by Stanbury JB, Wyngaarden JB, Fredrickson DS, New York. McGraw-Hill 1983; 881-905.

2. Kihara H. Genetic hetrogeneity in metachromatic leucodystrophy. Am J Hum Genet 1982; 34: 171-180.

3. Butterworth J, Broadhead DM, Keay AJ. Low arylsulfatase A activity in a family without metachromatic leukodystrophy. Clinical Genetics 1978; 14: 213-218.

4. Raghavan SS, Gajewski A, Kolodny EH. Leucocyte sulfatidase for the reliable diagnosis of metachromatic leucodystrophy. J Neurochem 1981; 36: 724-731.

5. Baum H, Dodgson KS and Spencer B. The assay of aryl sulphatases $A$ and $B$ in human urine. Clin Chim Acta 1959; 4: 453.

6. Suzuki K. Enzymic diagnosis of the sphingolipidoses in methods of Enzymology. Vol L (Complex Carbohydrates). ed. Victor Ginsberg 1978; 468-471.

7. Applegarth DA, Wood S, Toone JR. Manual of methods used to investigate biochemical diseases. Children's Hospital, Vancouver (1984).

8. Kihara $\mathrm{H}, \mathrm{Ho} \mathrm{C}-\mathrm{K}$, Fluharty AL, Tsay KK et al. Prenatal diagnosis of Metachromatic Leukodystrophy in a family with Pseudo Arylsulfatase A deficiency by the Cerebroside Sulfate Loading Test. Pediat Res 1980; 14: 224-227.

9. Poulos A and Beckman K. The rapid assay of cerebroside sulphate sulphatase using $(3 \mathrm{H})$ cerebroside sulphate as substrate. Clin Chim Acta 1978; 89: 417-420.

10. Lowry OH, Rosebrough NJ, Farr AL, et al. Protein measurement with the Folin phenol reagent. J Biol Chem 1951; 193: 265.

11. Stevens RL, Fluharty AL, Kihara H, et al. Cerebroside sulfatate activator deficiency induced metachromatic leukodystrophy. Am J Hum Genet 33: 900-906. 
12. Fujibayashi $S$, Inui $K$ and Wenger DA. Activator protein-deficient metachromatic leukodystrophy: Diagnosis in leukocytes using immunologic methods. J Pediatr 1984; 104: 739-742.

13. Harben AM, Krawiecki N, Marcus R, et al. A Km mutant of arylsulfatase A. Clin Chimica Acta 1982; 125: 351-354

14. Langenbeck V, Dunker P, Heipertz R, et al. Inheritance of metachromatic leukodystrophy. Am J Hum Genet 1977; 29: 638.

15. Kihara H, Fluharty AL. Letter to the Editor: Frequency of the PD allele. Pediatr Res $1980 ; 14 ; 890$.

16. Schaap T, Zlotogora J, Ellan E, et al. The genetics of the Aryl Sulfatase A Locus. Hum Genet 1981; 35; 531-539.

17. Feigin I. Diffuse cerebral sclerosis (Metachromatic leuko-encephalopathy). Am J Pathol 1954; 30: 715-737.

18. Bubis JJ, Adlesberg L. Congenital metachromatic leucodystrophy. Acta Neuropathol 1966; 6: 298-302.

19. Buonanno FS, Ball MR, Laster W, et al. Computed tomography in late-infantile metachromatic leucodystrophy. Ann Neurol 1978; 4: $43-46$.

20. Nyberg-Hansen R. Metachromatic leucodystrophy: Two unusual cases of the late infantile form. J Neurol 1972; 203: 145-154.

21. Dubois G, Turpin JC, Georges MC, et al. Arylsulfatases A and B in leucocytes: A comparative statistical study of late infantile and juvenile forms of metachromatic leucodystrophy and controls. Biomedicine 1980; 33: 2-4.

22. Peiffer J, Harzer K and Scholet W. Diffuse-Disseminated Sclerosis combined with a partial Arylsulfatase A (ASA) Deficiency. Mixed Heterozygosity of ASA- and Pseudo-ASA-Deficiency? Neuropediatrics 1984; 15: 59-62.

23. Vos AJM, Joosten EMG, Gabreels-Festen AAWM, et al. The diagnostic value of sural nerve biopsy in metachromatic leucodystrophy and other conditions with low leucocyte arylsulphatase A activities. Neuropediatrics 1982; 13: 42-47. 